\title{
Evolución del estilo y la estructura en José María Arguedas
}

\author{
Carlos Eduardo Zavaleta \\ Departamento Académico de Literatura
}

\begin{abstract}
A Luis Jaime Cisneros, maestro de críticos y escritores, $y$ de vida, diestro en el lenguaje y profundo en el pensamiento.
\end{abstract}

ID ropongo a los lectores efectuar un viaje de 1934 en adelante, a fin de 1 analizar a grandes rasgos la evolución del estilo y de la estructura en las narraciones de Arguedas, cuya carrera se inicia de modo muy humilde en relatos que difícilmente podemos llamar cuéntos, como son los recogidos por José Luis Rouillon. ${ }^{1}$

Sin embargo, de ese Arguedas dudoso y primerizo va a surgir gradualmente despierto un valioso escritor, a quien conoció y saludó mi generación de narradores de los años $50 \mathrm{~s}$, a los euales êl-nōs llamaba en broma "ustedes los técnicos" (por nuestra dedicación a Joyce, a Faulkner, a Hemingway, a Borges, etc.), para acabar él mismo, en su madurez, experimentando con el tema, el estilo, el orden temporal, la atmósfera, los personajes y el remate, y hallando, por lo demás, un camino propio, no sólo literario sino también cultural, válido para todo el país. En verdad, él fue valiente al desafiar la propia literatura indigenista y neoindigenista, y desafiar asimismo la hegemonía castellana y crear, no diré 'injertos' ni 'híbridos' porque suenan mal, sino puentes efectivos de comunicación entre el castellano y el quechua, por canales más profundos que los de Ciro Alegría o Enrique López Albújar. Al César lo que es del César.

Los liamados Cuentos olvidados, recogidos por Rouillon, aparecieron en revistas y periódicos de Lima y el Callao en 1934 y 1935 . Como novedades

José Luis Rouillon, Presentación y Notas críticas a la obra de José Marfa Arguedas, en Cuentos olvidados, por J.M.A. (Lima, Ediciones Imágenes y Letras, 1973), 138 p. Las cinco narraciones recogidas por J.L.R., son las siguientes: "Los comuneros de Ak'ola", "Los comuneros de Utej Pampa", "K'ellk'atay Pampa", "El vengativo" y "El cargador". 
principales ofrecen la humildad, quizá la ingenuidad narrativa y la discusión, dentro de sí mismos, de los componentes internos y externos de la narración, preguntándose el autor cuáles eran los más importantes.

De los cinco textos, los tres primeros se dedican exclusivamente a describir la vida y costumbres de los comuneros, esto es, de los miembros de las comunidades indígenas que él conoció de niño, entre ellas las de Ak'ola, de Utej Pampa y de K'ellk'atay Pampa. Hasta en los títulos sobresalen ellas; para el Arguedas inicial, pues, no es importante el personaje individual, ni sus retratos, o las pinturas del paisaje, sino el grupo mismo, la comunidad y sus inevitables problemas de injusticia y desigualdad frente al "principal", al mandón, y esos primeros textos breves acaban siempre en un choque dramático y sangriento en que los comuneros son vencidos. Sólo muy contadas veces le interesa describir de paso a un personaje, pues para él todos son iguales, y están unidos por el afecto que les tiene el narrador y cuya desgracia común lamenta con su obra. Sólo en el segundo texto, consagrado a los comuneros de Utej Pampa hay un esbozo de protagonista, de animados de la acción:

Don Victor era alto; en todo el distrito ningún hombre era de su tamaño, tenía espaldas anchas y un pecho redondo y carnoso; su cara estaba picada por la viruela y era llena y grande, nariz de killincho, y bajo su frente angosta, ardían sus dos ojos pequeñitos y brỉlantes. Don Victō había llegado hasta sargento en el Ejército, sabía leer y escribir y dice, una vez, le pateó a un oficial porque quiso abusar de un soldado utejino; le flajelaron, primero, le metieron a la cárcel y después lo botaron. ${ }^{2}$

Como se ve, la prosa es muy sencilla, coloquial, las frases no se adornan; parece que contara un niño y hasta se desliza un error ortográfico: "flajelaron" con jota.

No obstante esas armas ingenuas y aun pedestres, en el cuarto texto, "El vengativo"3 , el incipiente estilo, contando ahora las relaciones de una joven blanca con dos adolescentes, uno misti, y otro indio, se vale inclusive de una carta que se ofrece íntegra al lector, y en ella se encrespa el lenguaje, en una súbita ola de celos, de resentimiento, de prejuicios sociales y raciales, y final-

${ }^{2}$ Op. cit., p. 25.

${ }^{3}$ Op. cit., pp. 35-52. 
mente de furia, horror, asesinato y arrepentimiento, envuelta esta última en la complicidad de la amistad entre dos culpables, por encima de la ley. Este relato indica una clara lectura de Dostoievski, pues la fuerza de las pasiones del joven celoso lo llevan hasta el mareo, la inconsciencia, y el desmayo del futuro asesino:

Mi rabia había llegado a revelarse con mi resolución de matarla; si crecía, era colmado inmediatamente con la proximidad cada vez más inminente de la "hora". Era por eso que en cada minuto me sentía pasionalmente más grande, más alto, más feroz, sin perder mi equilibrio.

Por encima de los molles que dan sombra al camino en la entrada del Credo, vi avanzar la cabeza de ella; el potro negro que le regalé yo, mi gran potro negro, domado por Tomascha, estiró el cuello y relinchó, reconociendo al tordillo, su hermano de tropa.

Me estremecí. Era ella que entraba a la quebrada, a su tumba. El corazón me sacudió, como antes, cuando la vi llegar a los retamales de 'Sulkaray', donde la esperé para gozar de su vida. ¡Qué misterio es el corazón, hermano! Empecé a temblar a pensar de mi valentía. Vi amarillo, todo amarillo, como la tierra del barranco. La tempestad, azuzada durante diez horas, engrandecida en su escondite, apretada en la oscuridad del corazón, me sacudió a la vista de ella, hasta tumbarme. Se oscurecieron mis ojos: una película negra, danżante cubriở la clariđaddel cielo, y caí de espaldas sobre el căming. Puccinelli Converso "

Aquí no sólo el coloquio español ya ha sido logrado, sino que el lenguaje es dúctil y flexible para adaptarse a diversas situaciones, y lo mismo sucederá en el cuento final, "El cargador", sencillo en su estructura lineal y fácilmente comprensible en su manejo de la variante peruana del español.

En suma, cuando Arguedas se lanza a escribir Agua (1935) no es porque no supiera escribir bien el coloquio español-peruano (como muchos críticos lo han supuesto), sino porque desea experimentar su estructura y estilo por otros caminos -más íntimos y apegados al quechua- y seguir con su defensa social del indio y con la pintura de su intimidad (lo que es ya algo nuevo en el indigenismo). He aquí logros y conceptos que no debemos olvidar en el escritor inicial. En Agua no existe el Arguedas aprendiz, como yo también lo creí en

\footnotetext{
4 "El vengativo", op. cit., pp. 45-46.
} 
un tiempo, sino el Arguedas experimentador, que lo guiará a través de todos sus libros, quizá con la excepción de Yawar fiesta (1941) y El Sexto (1961), en que esa experimentación no alcanza los altos fines artísticos de los demás.

Esta visión del futuro no debe, tampoco, silenciar sus relatos primarios, simples, humildes, cuya primordial intención era denunciar los abusos de autoridades provincianas en una gran ciudad como Lima, que ya en 1934 despertaba políticamente de modo variado, violento y hasta bárbaro ante las convulsiones sociales, que por fin estallaron. Sin embargo, en el proceso de escribir, Arguedas fue creciendo en el manejo de la estructura (de las formas lineales, empieza luego por el contrapunto de la descripción y el diálogo, y acaba en la intercalación de cartas, y más aún, en el deseo de descubrir el lado psicológico y oscuro de la conducta humana en general), y del estilo, dominando por fin, así sea con sencillez, el coloquio popular de ámbito regional peruano y español.

Releer ahora sus cuentos de Agua (1935) es recibir el agua viva de un fresco manantial, todavía no hollado por las supuestas maestrías literarias. En su frescura e ingenuidad, en el torrente de la lengua mixta y ruda, sentimos la creación en su real autenticidad. El autor va describiendo paisajes, hechos y hombres (en verdad, sobre todo niños), en rápidos trazos de dibujante aligerado por la prisa, por subrayar lo esencial, los personajes hablan rudamente, casi en interjecciones, mezclando el castellano y el quechua; las escenas parecen cortadas abruptamente por hachazos e hilvanadas por una mano infantil pero habilísima. Las descripciones son poéticas, la economia verbal ha concertado la esencia con la belleza. $\AA$ ratos hay ingenuida ${ }^{r}$ y cierto sentido de cosas incompletas o quizá excesivas, porque los cuentos están escritos como si fueran novelas cortas, muy divididos por capítulos que detienen o cortan el argumento central. Pero quizá así lo sentimos porque su marca es la del cincel, no de la pluma.

Por algo el mundo que pinta es mayormente infantil, así sea que conozca, un poco de lejos, el amor. Los "escoleros" están por todas partes. Niñoshombres que buscan cambiar la sociedad. Pueden ser Juancha, Pantacha o Ernesto los pequeños héroes de esos pueblos que sufren entre la crueldad y el olvido. Pero siempre se darán con los representantes del pasado tradicional, como don Braulio o don Ciprián, que les negarán la felicidad y les ofrecerán el espectáculo infernal de la perversión y la maldad. La lucha está dada, y en el nivel humano, todavía no se ha alcanzado la dignidad. Y tampoco el amor, puesto que en "Warma Kuyay", la rivalidad entre un adolescente indio y un 
niño mestizo, pero occidentalizado, -no se manifiesta por la gran amistad que los une a ambos, y tampoco ninguno de ellos se comporta como un amante real que avance de hecho hacia la amada. Hay otros cuentos, de diversos autores, sobre amores de niño, que son una exhibición de tremendas pasiones, aunque, por supuesto, carezcan de la delicadeza y la profunda ternura del texto de Arguedas. Yo creo que él ha mezclado varios temas en este cuento, y que el del amor no es el principal, sino la descripción general del pequeño pueblo y las diversas relaciones, inclusive de niños, con la autoridad grosera, pedestre, injusta y cruel.

Lo cierto es que han pasado sesenta y cinco años de la aparición de Agua y el libro se mantiene en un sitial de consideración. He aquí el segundo gran paso estructural y estilístico. Respecto a la composición, no le importan ya a Arguedas las interrupciones, las rupturas de tiempo o espacio; y no le importa usar de nuevo, en los ratos de crispación, un lenguaje ingenuo e infantil:

Dos, tres balas sonaron en el corredor. Los principales, don Inocencio, don Vilkas, se entroparon con don Braulio. Los sanjuanes se escaparon por todas partes y no volteaban siquiera, corrían como perseguidos por los toros bravos de K'oñani; las mujeres chillaban en la plaza; los escoleros saltaron de los pilares. ${ }^{5}$

Y con este lenguaje senctllo describe inelusive escenas de humor:

\section{"Jorge Puccinelli Converso"}

Don Braulio parecía chancho pensativo; miraba el suelo con las manos atrás; curvo, me mostraba su cogote rojo, lleno de pelos rubios. ${ }^{6}$

Ahora bien, en un lapso de veinte años (entre 1934 y 1954), Arguedas sólo había publicado "Zumbayllu", como texto breve; pero éste se anunció como un fragmento de una novela desconocida. La expectación de sus lectores era notable, pues creíamos que su novela Yawar fiesta (1941) no era el punto alto que esperábamos. En esa incertidumbre publicó Diamantes y pedermales (1954), donde había un cuento nuevo, "Orovilca". El alma nos volvió al cuerpo. "Orovilca" es un cuento de tema y paisaje distintos a las narraciones andinas de Arguedas. Aquí, en un ambiente costeño, en pleno desierto que rodea a

5José María Arguedas, Amor mundo y todos los cuentos (Lima: Francisco Moncloa Edit., 1967), p. 35.
${ }^{6}$ Op. cit., p. 34. 
Huacachina, vemos una mayor preocupación por el lenguaje, una conquista visible y distinta por asimilar una prosa castellana, sin deformarla demasiado. Se ve la tendencia hacia la frase española no quechuizada, pero siempre dentro de una oralidad mestiza que él buscaba. En "Orovilca" hay una retórica más pulida y menos agreste que en Agua. De algún modo puede decirse que en "Orovilca" la intención poética se da mejor que en los textos previos. La prosa de Agua sería un diamante en bruto; en "Orovilca" ya está pulido. Y debido a este pulimento no vemos quechuismos ni "traducciones" del quechua, sin que tampoco se necesiten "glosarios". En una palabra, hay soltura de lenguaje y las frases se encadenan mejor que antes para lograr el ritmo de los párrafos.

De otro lado, hay una buena pintura de retratos, especialmente de Salcedo, de Wilster y del narrador. Las figuras están precisas, nítidas, los rasgos físicos y morales bien dados, y sobre todo hay una atmósfera lírica que va dibujando la fantasía, la cual brota del paisaje (y de la imaginación del protagonista, por supuesto), cuyo tratamiento merece una mención aparte.

Cosa rara en el Arguedas de los años 50s, el paisaje es costeño, y se describen con detallado pormenor el desierto y la arena, la tierra, las lagunas y animales (la víbora y el pájaro chaucato), creando especialmente una atmósfera mágica, de donde brotan los juicios de Salcedo, para quien el agua y el fuego se hallan en el desierto, y aquí se reúnen asimismo el amante y su sirena. Así, con este cuento, Arguedas đéja por un momento los cerros y alcanza un mundo misterioso, donde conviven por jigual hadas, dromedarios prehistóricos y hombres apasionados. Aquí Arguedas ha salido de su hábitat normal, como lo hará después en El Sexto y en El zorro de arriba y el zorro de abajo.

Por entonces, testigo de que nadie se había ocupado aún del estilo de Arguedas, publiqué en nuestra revista Letras Peruanas ${ }^{7}$, una reseña de Diamantes y pedernales, aunque en verdad se dedicaba a cotejar el estilo de Agua con el de "Orovilca". Me pareció que, mientras en Agua, Arguedas quechuizaba el castellano, volviéndolo áspero, telegráfico, a veces poético y otras infantil, "Orovilca" exhibía una tendencia opuesta, de aproximación al español castizo. En medio de esos extremos, el lector común de 1954 ignoraba aún cuál sería el estilo definitivo de la próxima novela de Arguedas, anunciada desde 1948 en revistas, y desde 1951, cuando Letras Peruanas publicó el capítulo "Zumbayllu".

7 Telémaco, seud. de C.E.Z., "José María Arguedas". Reseña a Diamantes y pedernales (Letras Peruanas N ${ }^{\circ} 12$, Lima, agosto, 1955, pp. 179-180). 
Un año antes, en 1950, en la revista Mar del Sur, en un ensayo, Arguedas había confesado lo siguiente:

La búsqueda del estilo fue ... larga y angustiosa... Realizarse, traducirse, convertir en torrente diáfano y legítimo el idioma que parece ajeno, comunicar a la lengua casi extranjera la materia de nuestro espíritu. Esa es la dura, la difícil cuestión... era necesario encontrar los sutiles desordenamientos que harían del castellano el molde justo, el instrumento adecuado. ${ }^{8}$

Pues bien, la nueva novela apareció finalmente en 1958. Los ríos profundos es de veras un triunfo estilístico y poético del autor, atrás quedan definitivamente los arduos años de aprendizaje. Tanto en la estructura del libro (la sucesión del desarrollo biológico, espiritual, religioso y de miembro del pueblo indio del protagonista Ernesto), como en la doble presentación del paisaje (objetivo o evocado), y en los retratos, la novela supera los alcances de toda obra previa. Y es en el lenguaje donde se notan más los logros: ya no vemos la áspera pugna entre el castellano y el quechua, sino que, resuelto el conflicto, el nuevo estilo, flexible y dúctil, domina las diversas situaciones, diálogos, análisis psicológicos y pintura de escenarios. Arguedas ya es capaz de darnos ironías, contrastes, vivencias íntimas, admirables paisajes, añadiendo a la vez una atmósfera tierna, o de angustia, o de alivio, que vive el protagonista en medio de su arduo aprendizaje, físico y espiritịal, de la juventud, dữante el cual debe vencer el ataque directo o disimulado "de "enemigos" 9 sea de personajes secundarios pero importantes. Por lo demás, ya no hay dudas ni asperezas en el estilo. Y al fondo del lenguaje, corre la oposición costa-sierra, así como discurren las otras oposiciones entre pureza y pecado, justicia e injusticia, miedo y libertad. La formación juvenil de Ernesto es una gran aventura, y al mismo tiempo, el proceso sirva para que el autor enriquezca la intimidad del personaje, cosa que pocas veces han hecho bien los indigenistas. Aunque, analizando toda la obra de Arguedas, sería muy mezquino llamarlo indigenista. Otros autores se han ocupado asimismo del angustioso proceso del aprendizaje juvenil, entre ellos Flaubert, Musil, Faulkner y Joyce, pero lo original en Arguedas es la marcha paralela de los acontecimientos individuales, y colectivos, que al final se juntan en un deseo de liberación popular, doloroso y hasta místico.

\footnotetext{
" José Marfa Arguedas, "La novela y el problema de la expresión literaria en el Perú", en Mar del Sur, Lima, enerofebrero, 1950, p. 70.
} 
Lo que se había confirmado con esta obra era la fuerza del neoindigenismo, surgido a comienzos de los años 50 s, merced a la visión de los jóvenes y del propio Arguedas, quien deseaba perfeccionar su labor creadora. Esa visión, a fin de superar el molde anterior, debía dosificar las descripciones del paisaje, potenciar las relaciones hombre-naturaleza como un binomio flexible, nada rígido, esmerarse en los retratos físicos y psicológicos, alterar el orden temporal y conceder a la atmósfera una vena india, tierna, dulce y mítica a la cual otros escritores, inicialmente indigenistas, no habían llegado.

Pues bien, todo eso hace ahora Arguedas. Sus descripciones son precisas y revelan ese hondo ambiente mestizo donde las cosas y los hombres se mezclan mucho más de lo habitual, e inclusive todo se humaniza y de algún modo se diviniza también.

Esa versatilidad le permite pintar los muros cusqueños de piedra con gran belleza (ver p. 10), o cotejar las piedras con los ríos (p. 11), o con la música (p. 16), o darnos la comunión total del hombre con la naturaleza (p. 17), o retratar espléndidamente al Cristo crucificado, y asimismo, a una humilde opa o tonta del pueblo (pp. 23-24, 200-201). ${ }^{\text {? }}$

Mientras tanto, el viejo estilo de Agua y Yawar fiesta, que ha sufrido toda una larga evolución, se hace muy flexible, como vemos en estas variaciones de formas verbales:

Tres depártamentos tuvimos que atravesar' a esa pequeña ciudad silenciosa. Fue el viaje más largo y extraño que hicimos juntos; unas quinientas leguas en jornadas medidas que se cumplieron rigurosamente. Pasó por el Cuzco, donde nació, estudió e hizo su carrera; pero no se detuvo; al contrario, pasó por alli como sobre fuego. ${ }^{10}$

Curiosamente, en estos inocentes cambios de formas verbales, se ve un antecedente de la insólita frase con verbos y tiempos entremezclados que usará Vargas Llosa desde la primera página de Los cachorros (1967).

\footnotetext{
9 José María Arguedas, Los rios profundos (Buenos Aires, Losada, 1958). Todas las citas respectivas se refieren a esta edición.

${ }^{10}$ Op. cit., p. 37. La cursiva es mía.
} 
Por fin, la estructura fragmentaria de Los rios profundos es la del contrapunto de escenas y capítulos diversos, no lineales, técnica asimismo musical. Si en los primeros capítulos se dan las relaciones de Ernesto con su padre, con su tío (El Viejo), y con el Cusco y Apurímac ancestrales, luego viene la "educación sentimental" del muchacho en el "satánico" colegio, donde se agudiza el contrapunto lingüístico entre los profesores españoles y los alumnos peruanos, pero también donde estallan el mal, la violencia y el pecado, sólo para despertar la bondad, la ternura, y aun la rebelión social en el espíritu de Ernesto. Arguedas desea enlazar esas peripecias con el motín de las chicheras, con la peste, la huida del protagonista, y finalmente en confluencia con la movilización de los colonos en busca de libertad y justicia.

Ahora bien, las mismas virtudes obtenidas en Los rios profundos son visibles en el espléndido cuento "La agonía de Rasu Ñiti" (1962). En verdad, su progreso en el cuento es asimismo notable. Si en 1954 publica "Orovilca", en 1955 aparece "La muerte de los hermanos Arango", que gana un premio en México, y en 1957 divulga "Hijo solo", y por fin, "El forastero" (1964), en Montevideo. En general, en este género, se ve mejor su acercamiento a la sintaxis española, pero sin renunciar a sus descripciones mágicas y a esa espiritualidad o animismo que envuelven a su autor con todas las cosas, vivas o inanimadas, desde que era niño.

Respecto a su penúltima novela Todas las sangres (1964), por falta de espacio, sólo diré que la conisidere etro gran experimento narrativo, una empresa difícil que ya no podía resolyerse con el lenguaje poético de Los ríos profundos, ni con los diálogos crưdos y aun bestiales de El Sexto, ni con la simple marcha de una narración lineal. Arguedas va más allá, busca un fresco pictórico, un despliegue de personajes, descripciones, modos de hablar peruanos, y diálogo y juicios sobre nuestra sierra todavía feudal y nuestra costa torpe, racista y presumida. Ese libro significó para él lo que La casa verde para Vargas Llosa: el tratamiento, por primera vez, de un mundo vasto y complejo. Y en segundo lugar, como otro mérito, ese fresco pictórico se da mediante una estructura de sucesos y anécdotas entrelazados donde el novelista ya no avanza linealmente, sino en un arquitecto que construye en diversos planos, y que no debe perder la visión del conjunto, esto es, el reunir a todo un país en medio de una vieja y renovada guerra moral y simbólica, entre el bien y el mal. He aquí un nuevo paso positivo en el manejo de la estructura.

Y también diré que no estuve ni estoy de acuerdo con que un grupo de investigadores sociales "juzgaran" esa novela como si fuera un tratado de so- 
ciología, cuando solamente es lo que debe ser, una obra de arte. Si analizáramos una novela fuera de su campo, estaríamos cometiendo el mismo error de Salvador de Madariaga cuando pretendió "juzgar" el Hamlet de Shakespeare como un doble tratado de psicología y filosofía.

Al desplegar su especie de mural, Arguedas necesita de varios personajes importantes, o sea, no sólo de retratos distintos, sino de actitudes y "voces" y aun tonos diferentes, tarea nueva que también resuelve. Y en cuanto a las ideas que cada personaje emite, oigámoslas como opiniones de cualquier hombre libre, y discutámoslas o no, pero no condenemos a su autor por emitir juicios a través de sus personajes. Esa es una costumbre ancestral en literatura, en una obra de ficción. Quienes hemos crecido leyendo a Unamuno, a Pío Baroja, a Aldous Huxley, a David Herbert Lawrence, a Cortázar o a Borges, no podemos sorprendernos de sus juicios contradictorios, de sus apasionadas discusiones. La literatura, como parte de la humanística, tiene pleno derecho a usar las ideas e inclusive el género del ensayo para ventilar juicios. Al contrario, es un triunfo que un escritor como Arguedas, tan sencillo, tan enemigo de pasar por hombre ilustrado y doctoral, explique al fin al lector to que piensa. En buena hora, y sigamos adelante con la última novela de nuestro autor, El zorro de arriba y el zorro de abajo. ${ }^{11}$

Al decidirse a escribir esta obra, según declaró desde 1968, como la vida del novelista y el texto se hallan tan entremezclados, en una técnica que es también la del contrapunto musical, alternando "diarios" afectivos con descripciones más o menos neutras, ¿bjetivas, es una necesidad para nosotros preguntarnos por el estado de ánimo de escritor. Sus diversas cartas dirigidas a su psiquiatra, la doctora Hoffman ${ }^{12}$, nos ilustran que Arguedas sufría, al parecer desde 1965, una nueva y aguda crisis física y moral, mucho más peligrosa que las antiguas. En verdad, él pasó por varias experiencias traumáticas desde su niñez y adolescencia. A mí, allá por 1953 ó 1954, me contó que la primera vez que estuvo en Lima, a comienzos de la década de los 30 s, se sintió tan abrumado-quizá por la muerte de su padre en 1932 o por el duro cambio a la gran ciudad--, que salió a pasear sin rumbo por las calles y perdió la memoria durante cuatro o cinco días, de los cuales no conservó ya recuerdos. Un joven así tenía que ser sujeto de grandes pasiones, desde la ternura y la bondad y la extrema amistad, hasta el

\footnotetext{
"José María Arguedas, El zorro de arriba y el zorro de abajo (Buenos Aires: Losada, 1971), 2a. ed.

12 John V. Murra y Mercedes López-Baralt, Las carıas de Arguedas (Lima: Fondo Editorial de la Universidad Católica, 1996), pp. 127-128, y 140-144. Respecto a la carta a su ex-esposa Celia, aparece en el Dominical de El Comercio, 28 de noviembre de 1999.
} 
ofuscamiento. Era muy callado, pero si subía a una tribuna, dictaba admirables conferencias, en que su erudición y su locuacidad, y su corrección idiomática, eran plausibles. Era callado y tímido, pero, en una gran reunión, si le pedían que cantase, él se abrazaba de la guitarra y la tañía con tal belleza, nostalgia y ternura que los oyentes daban gritos al oírle cantar; quizá como nadie, él nos transportaba a siglos atrás, en que había existido alguna felicidad en el país.

Para entender el sentido de la novela, debemos leer el impacto que produce Chimbote en el escritor (en especial las páginas 140 y 149), quien se deslumbra ante la nueva realidad económica y social que él desconocía. Por ejemplo, el jefe de una fábrica de harina de pescado dice al narrador-protagonista:

Pero no hemos subido aquí... a seguir discurseando sino para que usted conozca y vea lo que es una gran fábrica, cómo, ahora, que es más grande, la manejan un cuarto de obreros que antes. Y lo que Chimbote es de noche. Chimbote de noche somos nosotros, las fábricas de harina de pescado y aceite. Yo me carajeo del humo rosado de la Fundición que a usted lo impresionó. De noche, estas máquinas, nuestros muelles y las bolicheras tragan anchoveta y defecan oro; eso es vida, ¿no? Los otros, los comerciantes y los miles de hambrientos duermen en la oscuridad natural o en la oscuridad apagada. Aquí, en mi fábrica todo está prendido y no enconträrảhaúu nieun gringo, neuno solo... ${ }^{13}$

"Jorge Puccinelli Converso"
Ese "descubrimiento" de Chimbote le hace finalmente cambiar de proyectos literarios, pues él tenía pensado escribir sobre la caleta de Supe, adonde grande. De aquí en adelante, pospuso la tarea folklórica que le había llevado a Chimbote y nació en él esta nueva novela amorfa, heterogénea, única en nuestras letras, y juzgada por muchos como incompleta, si bien el crítico Lienhard aconseja leerla con la idea de que ha sido "terminada". Por mi parte, yo recomendaría leerla como si estuviese concluida, pues no tenemos otro camino sino respetarla tal como está.

El lúcido Lienhard, además, nos ha ilustrado muchísimo, no sólo sobre la fábula o leyenda de los zorros, que Arguedas bebió en un relato de 1600, sino cómo la picardía criolla encarna a esos "zorros" en la conducta habitual de diversa

${ }^{13} \mathrm{Cfr}$. El zorro de arriba..., p. 140. 
clase de peruanos actuales. He ahí otro modo de aprovechar en la ficción conocimientos de otras disciplinas, lo que vuelve a convertir a Arguedas en el experimentador de temas, estructuras y estilos de siempre, desde su primer libro. Incluso, en forma sorpresiva, pero natural, en un escritor latinoamericano, da su opinión sobre la ciudad de Nueva York, por ejemplo (ver p. 97). Por todas estas razones, se hallan muy equivocados quienes suponen que este libro muestra cierta decadencia narrativa de Arguedas; al contrario, aquí él busca, hurga, halla y retuerce muchas formas de describir y dialogar, y revela en cada una de ambas secciones (los "diarios" personales y las narraciones objetivas), gran libertad de temas y estilos. El contrapunto de las dos secciones, es seguido por el contrapunto de dos lenguajes principales, el culto y el popular, y dentro de éste, aparecen las distintas "jergas" de los grupos de pescadores y de jefes mafiosos, sin olvidar la carga violenta y sexual de cada grupo. Aquí está la vida "salvaje" en que el "capo" es capaz de "comerse" a un subordinado, vida propia que surge de los bares, las apuestas, las prostitutas y el alcohol. Ningún otro escritor ha descrito ese panorama de "fuerzas" que actúan sobre Chimbote y el Perú. Y por otra parte, frente al diálogo popular y licencioso de los obreros y sus "capos", se halla el lirismo y laternura de los "diarios"; en el libro, las dos mitades luchan lingüística y simbólicamente entre sí. Es como si "vida" y "arte" estuvieran separados por la lucha económica provinciana.

Para quienes se interesan sôlo en el argumento y lo llaman incompleto, en el texto "¿Último diario?" está el proyecto de las escenas faltantes; y en cuanto a la postura intelectual del escritor, Lienhard añade que aquí Arguedas no practica un "indigenismo paternalista", ni es una voz que habla en vez de los explotados, sino que, junto con la suya, habian también los explotados indios; es decir, les ha dado a éstos la libertad que no les concedieron los autores llamados indigenistas a secas.

En una palabra, Arguedas no se apagó luego de Todas las sangres, dolido por el ataque de los sabihondos sociólogos, sino que surgió con un proyecto aún más experimental, valiéndose inclusive del ensayo como arma novelística, y defendiendo su posición personal de modo extremo, por lo cual los editores de la novela han hecho bien en publicar un Epilogo, donde constan las últimas decisiones del escritor que va camino del suicidio, así como el oportuno texto de su discurso "No soy un aculturado", donde defiende al escritor peruano, cargado de temas propios, testigo de la vida de "picaflores que llega hasta el sol para beberle su fuego y llamear sobre las flores del mundo", sino a quien sólo le faltarían técnicas ajenas, pero no esencias. Creo que esta opinión suya la hemos confirmado con su obra y con la de nuestra generación de narradores de los años 50s. 